\title{
Especificidade da Contribuição dos Saberes $e$ Práticas das Ciências Sociais e Humanas para a Saúde'
}

\section{Specificity of the Contribution of the Knowledge and Practices of the Social and Human Sciences to Health}

\author{
Madel Therezinha Luz \\ Doutora em Política. Professora Titular do Instituto de Medicina So- \\ cial da Universidade do Estado do Rio de Janeiro. Aposentada. \\ Endereço: Instituto de Medicina Social da UERJ - Rua São Francisco \\ Xavier, 524, Pavilhão João Lyra Filho, 7 andar, Bloco D, Maracanã, \\ CEP 20550-900, Rio de Janeiro, RJ, Brasil. \\ E-mail: madelluzœuol.com.br \\ I Texto elaborado a partir de apresentação no II Encontro Paulista \\ de Ciências Sociais e Humanas em Saúde, junho de 2009.
}

\section{Resumo}

0 artigo trata de questões envolvendo a vida, a saúde e o adoecimento na sociedade atual. Tenta esclarecer as contribuições das ciências humanas e sociais na construção do campo da saúde - principalmente o da saúde coletiva - tanto em nível da pesquisa empírica como nos planos teórico e metodológico. Tenta mostrar que tanto categorias analíticas e conceitos como estratégias metodológicas das ciências sociais e humanas são úteis para o esclarecimento de relações entre condutas, estilos de vida, trabalho, valores culturais e o processo saúde/doença. Tenta também demonstrar que esse grupo de ciências tem suas próprias formas de expressão e estilo de difusão de conhecimento, que nem sempre são aceitas pelas ciências duras do campo da vida e da saúde, incluindo a medicina e a epidemiologia. Apesar de sua real contribuição para o avanço do campo, podem ser "acusadas" de falta de objetividade ou precisão. Os cientistas sociais da saúde coletiva têm que demonstrar, muitas vezes, que os resultados de suas pesquisas, e seu estilo de difusão, são tão científicos quanto os das disciplinas duras.

Palavras-chave: Ciências Sociais; Saúde; Campo; Contribuição. 


\section{Abstract}

This article deals with questions concerning life, health, and getting ill in the current society. It tries to show the contributions of the social and human sciences to the construction of the health field -mainly public health- both in the level of empirical investigation and in the theoretical and methodological ones. It tries to point out that the analytical categories and concepts, as well as methodological strategies of the human sciences are helpful to explain relationships between conducts, lifestyles, work, cultural values and the health/disease process. It also attempts to demonstrate that this group of sciences has its own forms of expression and style of knowledge diffusion, which are not always accepted by the hard sciences in the life and health fields, including medicine and epidemiology. Despite their real contribution for the advance of the field, they can be "accused" of not being objective or exact. The social scientists of the public health field have often to prove that the results of their studies or their own style of expression are as "scientific" as those of the hard disciplines.

Keywords: Social Sciences; Health Field; Scientific Contribution.

\section{Ciências Sociais na Área da Saúde: por que e para que?}

Cresce continuamente na sociedade contemporânea a busca por "cuidado à saúde", isto é, o apelo social à atenção médica e a programas de prevenção e promoção de saúde a indivíduos, grupos e comunidades. Essa busca pode ser vista como uma resposta cultural ao aumento exponencial, nas últimas duas décadas, do sofrimento e adoecimento humanos, fruto das condições sociais adversas à vida (danos evitáveis, oriundos do modo social de viver, ao meio ambiente, aos seres humanos de todas as idades em sua trajetória vital e aos seres vivos em geral) características do mundo urbano atual (Luz, 2005a).

Além das conhecidas doenças crônico-degenerativas - antigas e recentes -, em progressão constante numa população mundial tendente ao envelhecimento, acrescentam-se a volta de antigas endemias, ou de epidemias consideradas praticamente extintas pelos órgãos sanitários internacionais, como a tuberculose, a sífilis, a malária, e mesmo o sarampo e a rubéola, entre tantas que reaparecem no cenário da saúde pública. Há uma inegável degradação das condições de vida, com o crescimento da pobreza no mundo capitalista em crise. Degradação gerada, em grande parte, pela ordem social do trabalho vigente no sistema de produção globalizado (Luz, 2003, 2004, 2005a, 2005b, 2005c, 2007).

Acrescem-se aos problemas provenientes de processos patológicos, crônicos ou agudos, os gerados pela violência e pelo próprio ambiente de trabalho, como a instabilidade do emprego, a supressão de direitos trabalhistas históricos, e a consequente generalização da insegurança social (Castel, 1995, 2003). Esses problemas têm nítida repercussão no agir da vida cotidiana e na saúde das pessoas, tanto no plano coletivo como no individual. Costumam ser analisados, no campo das ciências sociais, como "macrossociais", sendo denominados, na área da saúde pública, "determinantes sociais da saúde".

Expressam, é verdade, a exclusão do núcleo central do sistema econômico, de crescentes segmentos populacionais, mas exprimem também a avassaladora presença, em todas as formas de interações sociais, dos valores mortíferos (antipessoais e antissociais) predominantes em nossa sociedade: 
o individualismo como imperativo social, o estilo diferenciado de consumo como forma de atribuição de status e prestígio social, a competição, desprovida de parâmetros éticos, envolvendo as pessoas num contínuo processo de autofagia simbólica (exclusão ou morte do outro) em todos os campos do viver, inédito, talvez, na história da humanidade, excetuada uma hipotética fase da evolução humana, não comprovada em termos históricos, etnológicos ou arqueológicos, da denominada "horda antropofágica”.

Nas teorias sociais evolucionistas do século XIX, seja a anglo-saxônica, tipificada em Arnold Toynbee, seja a marxista, exemplificada em Engels, concebiam-se fases de evolução da sociedade humana, em que a "horda primitiva" seria um momento pré-civilizatório, do qual a prática do canibalismo faria eventualmente parte. De fato essa prática, com finalidades culturais e rituais simbólicas importantes, existiu em diversos momentos da história humana, em sociedades e culturas diversas, com distintos graus de complexidade civilizatória, em tudo diferentes dos da sociedade em que vivemos.

O nível não apenas constante, mas ascendente, nas últimas décadas, do estresse advindo das condições socioeconômicas e culturais sobre os agentes encarregados do trabalho intelectual, principalmente o universitário - sobretudo na área de saúde, nosso universo de interesse e pesquisa há alguns anos -, e a influência desse estresse na manifestação de diversas formas de adoecimento dos profissionais da área, tanto aqueles voltados para a área de atenção como os do ensino e da pesquisa, tendem a exprimir-se em termos de sintomas das doenças crônicas já mencionadas. Voltemos às principais: as cardiovasculares (cujo sintoma mais constante é a hipertensão arterial), a diabetes, os reumatismos e os cânceres. Mas explodem também em episódios agudos de adoecimento orgânico, como nos enfartes, nos acidentes vasculares cerebrais, nas tendinites, nas doenças caracterizadas por dor prolongada e dificuldade de movimentarse, como nas doenças do assim chamado aparelho musculoesquelético: as DORT, antes denominadas LER, a fibromialgia (síndrome caracterizada por dor generalizada e fraqueza muscular), as ligadas ao aparelho digestivo (doenças do refluxo gastro- esofagiano) etc. Mencionemos também o aumento de distúrbios psíquicos, tais como a depressão crônica, as fobias, as crescentes sociopatias, os processos caracterizados por ansiedades, vistas na infância como "hiper" ou "hipo" atividades (muito precocemente controladas com fármacos), as síndromes de pânico, as síndromes metabólicas ou digestivas, com todo seu cortejo de somatizações. Quase todas essas formas de adoecimento estão presentes nesses profissionais. Levantamentos populacionais epidemiológicos, tanto como estudos clínicos divulgados pela imprensa escrita e televisiva, as mencionam incessantemente.

Pode-se argumentar, não sem razão, que esses profissionais não fogem ao perfil dos demais, visto que a situação de estresse como condicionante do adoecer é característica universal, comum aos trabalhadores, sobretudo os de "atividades imateriais", atualmente dominantes na produção (Porchman, 2008). O processo que torna quase todas as atividades de trabalho "não físicas" é fruto da aceleração técnica da produção, uma consequência da automação (e informatização) do processo de trabalho, tendo relevante papel no aumento de produtividade. Produtividade exigida de cada trabalhador exercendo atividades, sejam elas "materiais" (físicas) ou “imateriais” (técnicas) (Porchman, 2008).

Pode-se argumentar, inclusive, com fundamento empírico, que a força de trabalho - e o organismo humano que a conforma e sustenta - não estava preparada para a revolução tecnológica implicada nas novas formas de desenvolvimento das atividades, nem da transmissão e difusão virtual da informação, cujo fruto principal foi exigir dos homens que produzam mais e melhor em espaço de tempo menor, com aceleração acentuada de seu ritmo de atividades, mas sem remuneração correspondente à produção agregada, nem consideração pelo descanso ou segurança do trabalho desempenhado com o novo ritmo (Luz, 2004, 2005b).

Nosso ponto de interesse aqui, em perspectiva sociológica, é que o sofrimento e o adoecimento provocados por essa situação, ao mesmo tempo complexa e dramática para a vida humana, individual e social, ao invés de suscitar equacionamento e resolução através de políticas sociais de trabalho sustentadas, ou em formas civis estáveis de organi- 
zação, manifestas em movimentos sociais, ou numa busca coletiva, ainda que pontual, de soluções solidárias, mesmo provisórias, têm buscado âncora no campo das ciências da saúde, em todas as suas áreas (sobretudo na medicina), especialmente concentrada na área da Saúde Coletiva.

Como consequência, todo o mal-estar social gerado pela sociedade contemporânea é formulado em termos de "saúde" e, em grande parte, em termos de "saúde coletiva”. Não é propósito deste texto discutir a problemática da "medicalização social" ou a polêmica da "heteronomia social", que se desenvolveu desde os anos 1970 com autores como Illich, Dupuy e Foucault, já comentada em trabalhos anteriores (Luz, 2007, 2008). Talvez o que tenhamos que considerar são as consequências sociais do desdobramento atual do processo.

Consequentemente há, de nosso ponto de vista, um processo social em marcha que tende a concentrar em um conjunto de instituições específicas os “nós górdios” sociais, isto é, não solucionáveis, da presente formação social, ou pelo menos ainda não equacionados em termos sociais. E aqui se abre um grande desafio para as ciências sociais e humanas. Pois cabe a um grupo de disciplinas deste campo: Sociologia, Antropologia, Política, História, Psicologia e Filosofia, para citar as principais, debruçarem-se sobre a "questão da saúde e doença" na vida social contemporânea. De fato, cabe a essas disciplinas, com seus objetos e métodos próprios de pesquisa, trabalhar as questões relativas à vida humana em seu aspecto relacional grupal, comunitário, coletivo. As disciplinas tradicionais da área da saúde estão ligadas umbilicalmente à biologia, quando não à física clássica. Acreditamos que por seu olhar puramente natural e técnico sobre a vida, tanto do ponto de vista metodológico como epistemológico, essas disciplinas são incapazes de abarcar a totalidade do fenômeno da vida humana, sobretudo quanto aos aspectos mencionados acima (Luz, 2005a, 2008).

Por essas razões, entre as outras mencionadas, as ciências humanas e sociais vêm sendo solicitadas a trabalhar em regime de cooperação interdisciplinar de forma crescente no campo da saúde, sobretudo nessa área denominada saúde coletiva. O VIII Congresso Brasileiro de Epidemiologia da ABRASCO, por exemplo, realizado em Porto Alegre no ano de 2008, tematizou em mesas redondas, painéis e comunicações orais, a colaboração interdisciplinar com as ciências humanas e sociais, testemunhando essa tendência.

A ampliação atual inegável do "olhar humano e social" nas biociências e na medicina, mesmo na área da clínica e da cirurgia, é uma clara demonstração da utilidade e do benefício que oferecem as ciências sociais e humanas em geral à Saúde como área de conhecimento e de prática profissional. Mas é também inegável o benefício da ampliação de fronteiras epistemológicas e metodológicas que representa para os cientistas sociais o fato de debruçarem-se sobre as disciplinas tradicionalmente ligadas à vida e à saúde humanas.

\section{As Ciências Humanas e a Cultura da Saúde no Mundo Contemporâneo}

Deve ser ressaltado o período crescente, apesar de recente, de tematização e preocupação, em termos de pesquisa, da parte das ciências sociais e humanas, envolvendo a vida, a saúde e a doença em nossa sociedade, sobretudo na cultura contemporânea. Éverdade que disciplinas como a demografia, a geografia humana e a história contribuíram em muito para o nascimento de outras do campo da saúde, como a epidemiologia social e a medicina do trabalho, e foram úteis as narrativas de naturalistas e escritores para a clínica e a medicina social, dos séculos XVII ao XIX. Mas disciplinas como a sociologia e a antropologia, assim como a filosofia, vieram a se ocupar das questões da vida, da saúde e do adoecimento apenas no século XX, e mais especificamente após a segunda guerra mundial (Herzlich, 2004, 2005), com escolas de pensamento, como a funcionalista americana, que começa a tematizar as instituições médicas, vistas como "sistema social", como o hospital, a analisar os papéis sociais do médico e do paciente na consulta etc.

Talvez seja mais exato situar o boom dessas preocupações na sociologia e (em seguida) na antropologia no fim dos anos 196o, não sem relação com o movimento de contracultura que varreu o mundo ocidental no final da década, movimento com forte teor antitecnológico e naturalista, em que se percebia a medicina como estratégia de 
tecnificação da vida humana e de heteronomização da saúde. Filósofos, como Foucault e Illich, além de sociólogos e antropólogos, como Jean Pierre Dupuy e Luc Boltanski, que se tornaram muito conhecidos entre nós, acentuaram fortemente, nos anos 1970, o processo de dominação da vida pelas instituições ligadas ao saber e à prática médica, no correr do século XX.

$\mathrm{Na}$ área da antropologia das doenças abriu-se, neste momento, um grande campo de trabalho, sobretudo na França, mas também na antropologia anglo-saxônica. A antropologia se ocupará, a partir de então, com grande empenho, dessa área. Mas a área disciplinar das ciências sociais voltadas para as doenças não é necessariamente uma área voltada para a vida ou a saúde. Nesse mesmo período, a psiquiatria social, por exemplo, participa do movimento de reforma institucional na Europa (e nos Estados Unidos, através de alguns autores) e da transformação do saber (teoria e prática) psiquiátrico. A doença mental passará a ser pensada de maneira diferente da psiquiatria clássica, e mesmo da psicanálise, retirando do doente o caráter de estigma da loucura, abrindo caminho para saberes e práticas em saúde mental.

Enquanto isso, a sociologia continuou se ocupando do estudo das instituições médicas, das relações entre médicos e pacientes como atores sociais, dos modos de adoecer de pessoas e de coletividades na sociedade atual (ou na história da sociedade moderna), das descrições ou narrativas desses processos e de sua subjetivação, bem como das políticas de saúde, isto é, das formas como o Estado trata a questão do adoecimento coletivo.

Ao mesmo tempo pode-se observar, a partir do fim dos anos 1970, na América Latina e na Europa, o forte movimento teórico, social e profissional da saúde coletiva. Um novo campo de saberes e práticas interdisciplinar (na década seguinte também transdisciplinar) iniciou seu caminho, indo além da Saúde Pública ao tematizar não apenas doenças coletivas, como políticas públicas e formas inovadoras de atendimento a pessoas e grupos, como modos de comportamento, representações sociais e subjetividades de doentes; sobretudo, o significado que pode ter para os sujeitos das políticas médicas: saúde e vida.

\section{As Ciências Sociais e sua Intervenção na Ordem da Vida: desafios do contexto contemporâneo}

As ciências sociais e humanas tiveram e continuam a ter um papel importante no contexto desse desenvolvimento, tanto em nível metodológico como conceitual, sobretudo a partir dos anos 1980. Disciplinas como a Política, a Sociologia, a Antropologia, a Psicologia e a Filosofia trouxeram grande contribuição às áreas temáticas que começavam a se expandir na década de 1980 e que desde então não cessaram de aumentar: políticas e serviços de atenção à saúde: sexualidade, gênero e reprodução humana; violência doméstica e social; epidemias em que comportamentos e representações sociais estão fortemente implicados, como a AIDS; doenças sexualmente transmissíveis, consumo de drogas; intervenção biotecnológica nos corpos, práticas de saúde corporais, busca das chamadas medicinas ou terapias alternativas; síndromes atuais envolvendo a corporeidade etc.

As ciências sociais têm contribuído, nos estudos desses eixos temáticos, não apenas com metodologia de pesquisa ("técnicas qualitativas"). Do nosso ponto de vista, é sobretudo no olhar disciplinar dessas ciências, centrado na compreensão e na interpretação dos fenômenos socioculturais ligados à saúde e ao adoecimento, isto é, nas suas abordagens conceitual e metodológica, que reside sua maior contribuição à vida humana contemporânea.

Debruçando-se sobre as questões da vida coletiva, que atingiram na sociedade atual um papel dramático, em que a sobrevivência da espécie parece estar, muitas vezes, ameaçada por questões como a fome, a guerra, a violência generalizada, a exclusão, o sofrimento e o adoecimento coletivos gerados pelo trabalho, as ciências humanas assumiram o papel que lhes cabe face à saúde e à vida, retomando o pensamento clássico do século XVIII, em que questões envolvendo a população e a vida humanas foram analisadas como temas profundamente imbricados nos escritos dos teóricos, tanto no campo da filosofia social, como da economia política.

Mas talvez tão importante quanto a contribuição 
especificamente acadêmica tem sido a mutação do "olhar disciplinar" que as ciências humanas e sociais têm provocado na práxis do campo das profissões de saúde, isto é, no agir cotidiano dos profissionais da área. De fato, a incorporação, na prática desses profissionais, de instrumentos de apreensão e interpretação de questões postas pela atenção à saúde e pelo suscitar diário de problemas institucionais relativos ao campo, que as disciplinas originárias de formação não têm como equacionar nem solucionar, tem posto em relevância uma contribuição de "tecnologia social” neste agir, embora ainda sem um reconhecimento institucional consequente do campo da saúde.

As ciências sociais têm tido, assim, relevante papel para instrumentar conceitualmente políticas inovadoras de saúde, que levam em consideração a participação, como atores, de pacientes e de coletivos de usuários, ao incorporar categorias das ciências humanas, como as de sujeito, sofrimento e cuidado, na atenção à saúde de pacientes, ou as de democratização, participação, sociedade civil e controle social nas políticas de Estado pela população. Têm tido também importante papel como indicadoras dos problemas mais evidentes nessas políticas, originando direta ou indiretamente políticas alternativas. Em termos de metodologia, vêm oferecendo instrumentos de pesquisa, como as etnografias, por exemplo, para um campo antes fechado em estudos quantitativos empíricos, operativos ou meramente descritivos ("agregação de dados"), despidos de necessárias interpretações em termos sociais e culturais.

\section{Especificidade da Produção do Conhecimento das Ciências Sociais e Humanas na Saúde Coletiva: o duro processo histórico de reconhecimento institucional da área}

Uma questão frequentemente levantada pelos cientistas sociais da saúde coletiva face ao instrumental teórico e metodológico da área incorporado pelo campo da saúde coletiva é a do uso inadequado ou redutor desse instrumental. As categorias de análise ou instrumentos metodológicos seriam reíficados, isto é, transformados em "verdades" políticas ou (aparentemente) teóricas, visando a justificar projetos inovadores ou formas de intervenção profissional específicas que não teriam normalmente passagem política ou técnica diante dos programas ou serviços tradicionais de saúde. Também em dissertações ou teses de doutorado do campo da Saúde Coletiva aparecem, segundo os professores orientadores da área de ciências humanas, essas mesmas distorções teóricas ou metodológicas, que substancializam conceitos ou métodos, transformando-os, assim, em senso comum douto ou em ideologia.

Os cientistas sociais e humanos "estrito senso", isto é, que não pertencem ao campo da saúde, tendem a não considerar a produção proveniente da área como efetivamente pertencente ao seu campo, tratando-a como "nativa"; e com relativa frequência a ignoram em sua bibliografia quando realizam pesquisas sobre o tema da saúde. Isso é mais frequente na ciência política, mas é usual também em relação à sociologia e à antropologia da saúde. Os cientistas sociais que trabalham na área da saúde sofrem, desse modo, dupla depreciação em relação a sua produção científica. Em primeiro lugar, por serem as ciências sociais do campo da saúde vistas, embora não o sejam, como uma "área aplicada" à saúde e suas instituições. Mas as ciências sociais são, nesse caso, um subcampo da saúde coletiva, com atividade interdisciplinar de pesquisa, em que metodologias, abordagens conceituais e olhar interpretativo são as ferramentas teóricas e metodológicas do trabalho das ciências humanas na construção de objetos nesse campo. Em segundo lugar, por seus trabalhos não se enquadrarem, em termos de linguagem e metodologia, na área "dura" das ciências biomédicas, são vistos como "pouco rigorosos”, isto é, redutíveis à subjetividade, ao não mensurável, portanto, ao não objetivo, respeitadas as concepções e a sinonímia da área biomédica entre termos como objetividade, naturalidade, mensurabilidade e rigor.

A produção das ciências sociais se faz no sentido da compreensão e interpretação dos fenômenos da vida, do adoecimento e da morte humanas em sua relação com a cultura, com a sociedade, com os outros (seres humanos): com o outro, em última ins- 
tância. Seu paradigma não inclui, de forma alguma, a eficácia, que supõe a intervenção, o que é típico do pragmatismo das ciências ligadas à vida, isto é, de sua conservação, ou sua recuperação, como é o caso da medicina (ou das medicinas, para sermos mais rigorosos). E esse paradigma se exprime cientificamente, em linguagem específica, também diferindo da linguagem objetivante das ciências da vida, no sentido biológico do termo. Tem uma escritura (estrutura discursiva) adequada a sua epistemologia e formas de expressão e difusão de produtos científicos distintos dos da área biomédica.

Dentre os produtos específicos da produção da área deve ser destacado, por sua importância e valor secular na expressão das ciências humanas, o livro. Seja o livro "de autor", em que um pesquisador narra os resultados de sua pesquisa, teórica ou empírica, ou a coletânea de capítulos, em que vários autores narram no volume sua experiência em um tema de pesquisa comum. Esses são os dois produtos fundamentais na expressão das ciências sociais (sem menosprezo pelo artigo, produto tradicional e em grande crescimento na área) e são geralmente considerados menores no campo das ciências da saúde, quando não são descartados como produção científica. Já a grande árvore do conhecimento ligada à vida, que inclui não apenas as disciplinas ditas básicas (microbiologia e fisiologia, por exemplo) como as especialidades médicas, prioriza, como produto nobre de suas atividades de pesquisa, em acordo com as disciplinas "exatas" ou "duras", o artigo (individual ou coletivo) publicado em periódico indexado em bases de alto padrão (“qualificado"), pontuado a partir de cálculos estatísticos complexos sobre a divulgação do veículo e seu impacto (aceitação) na comunidade dos pesquisadores de determinada disciplina. Diante desses critérios, o livro, no limite, pode não ser considerado produção científica, expressando, dessa forma, a hegemonia atual de um tipo específico de expressão discursiva sobre o conjunto de expressões das disciplinas que conformam a "árvore das ciências".

Deve ser ressaltado, entretanto, que atualmente está em curso um processo de transformação desses critérios; a avaliação do livro como produto de mesmo valor científico que artigos originais, mesmo em disciplinas duras, está em processo, por reivindica- ção de pesquisadores e coordenadores de programas de pós-graduação e por iniciativa da CAPES (órgão do Ministério da Educação do Brasil que avalia os Programas de Pós-Graduação do país).

Em outras palavras, existe ainda a hegemonia da linguagem de um conjunto de disciplinas de um campo específico de conhecimento ("físicas" ou "exatas") sobre as outras, de outro campo ("humanas"). Embora essa seja uma questão posta desde fins do século XIX, é no decorrer do século XX, com o avanço das ciências "duras", seu envolvimento progressivo com a tecnologia e a linguagem esotérica especializada que a caracteriza, que se solidificou a dominância de um estilo de linguagem técnica (ou mesmo formal) dos papers sobre a linguagem das ciências humanas, expressa nos livros. Essa linguagem dos livros passou a ser, por sua vez, identificada com "arte", com todas as consequências epistemológicas e político- institucionais que isso implica. Pois a arte, na sociedade científica da modernidade, não produz conhecimento (verdades): produz apenas beleza, a ser apreciada (subjetivamente) por sujeitos individuais ou grupos de indivíduos (Luz, 1988, 2008).

Apesar de tantos entraves, as ciências sociais têm gerado, com sua intervenção, mais produtos que o artigo, o livro ou o capítulo de coletânea, fruto de sua diversificação metodológica. O método da pesquisa-ação, para dar um exemplo, ou o dos grupos focais, tem tido como fruto possível a modificação de situações institucionais ou sociorrelacionais, através de técnicas investigativas que são ao mesmo tempo modos de investigação e formas de participação/intervenção em situações concretas. Finalmente, certos projetos de programas de atenção ou de políticas de cuidado emergem de práticas de pesquisa inovadoras, não convencionais, mas que são, entretanto, técnicas de investigação das ciências sociais.

Essa verdadeira tecnologia social, oriunda das ciências humanas, é raramente mencionada como produto técnico/científico. É necessário começar a fazêlo, pois tem gerado conhecimento inovador no campo da Saúde Coletiva. Não podemos nos esquecer de que, na cultura contemporânea, ciência, tecnologia e inovação são praticamente sinônimos, e a inovação está associada a resultados concretos de intervenção de pesquisa em situações concretas, geralmente de 
natureza social, ainda que se expressem em termos de vida/saúde, doença/morte. Acreditamos que, na medida em que se ignoram os avanços produzidos no campo da saúde devido a essas intervenções, ignorase também a contribuição das ciências humanas para o avanço da área da saúde. Com isso retarda-se o processo de reconhecimento institucional das ciências humanas no campo. É como se, similarmente à tortura de Sísifo, a área tivesse sempre que voltar a "provar" que seu conhecimento e seus produtos são realmente científicos.

\section{Institucionalização das Ciências} Humanas e Sociais no Campo da Saúde: o papel da Associação Brasileira de Pós-Graduação em Saúde Coletiva (ABRASCO)

A ABRASCO, apoiada financeiramente pelo CNPq, realizou entre 2008 e 2010 uma pesquisa avaliativa sobre a expansão e o desempenho, no último decênio, da Saúde Coletiva como campo de conhecimento científico e de intervenção tecnológica e social na área da saúde, coordenada por Maria Cecília Minayo. Uma avaliação da década anterior já havia sido feita, coordenada pela mesma pesquisadora. 0 crescimento específico da área de ciências sociais e humanas teve seu papel avaliado na visível expansão quantitativa e qualitativa do campo.

Não é propósito deste texto percorrer o itinerário das ciências sociais e seu avanço na Associação Brasileira de Pós-Graduação em Saúde Coletiva, fundada há três décadas. Desde seu momento inaugural a área esteve presente nesse campo, através de um núcleo poli-institucional de cientistas sociais que se esforçavam por fazer valer os créditos das ciências sociais no campo da Saúde, sobretudo os relativos ao ensino e à pesquisa nas faculdades de medicina, nos departamentos de medicina preventiva, nas escolas de saúde pública etc.

É difícil nomear o núcleo inicial de cientistas sociais do campo da Saúde Coletiva sem deixar injustas lacunas. Vale a pena, entretanto, arriscarmo-nos a citar nomes que continuam em evidência no campo, tais como: Amélia Cohn, Ana Canesqui,
Eduardo Stotz, Everardo Duarte Nunes, Marcos de Souza Queiroz, Maria Andréa Loyola, Maria Cecília de Souza Minayo, Maria Augusta Olivo, Paulette Goldemberg, Regina Marsiglia, Rubens Adorno, Solange L'Abbate, Sonia Fleury. Não se pode esquecer da inspiradora presença da socióloga Cecília Donnângelo, que antes mesmo que existisse a ABRASCO, nos anos 1970, já contribuía para a presença da sociologia na área da saúde, tendo formado uma geração de pensadores e pesquisadores do campo da saúde coletiva. Seria também injusto passar em branco a efetiva contribuição para o crescimento da área das ciências humanas e sociais em saúde que há mais de duas décadas vem sendo dada por alguns “médicos preventivistas", chamemo-los assim. Entre os principais, destaquemos os mais conhecidos: Naomar de Almeida Filho, Jairnilson da Silva Paim, Lilia Blima Schraiber e José Ricardo Ayres. Há, é certo, uma nova geração de pesquisadores seguindo este caminho com o mesmo esforço e brilho, mas estamos nos referindo, aqui, ao núcleo formador deste subcampo.

Também em relação às políticas e instituições de saúde, juntamente com outros colegas, fizemos parte dos momentos inaugurais e de sua evolução, com a organização de eventos, tais como: Reuniões, Seminários, Congressos etc., envolvendo a legitimação da área de ciências humanas no campo da Saúde Coletiva, tanto no Brasil como na América Latina.

Além dos eventos nacionais e regionais brasileiros, a ABRASCO envolveu-se com a produção, a organização acadêmica e o patrocínio de reuniões latino-americanas de Ciências Sociais e Saúde. Como exemplo deve ser citada a compacta e abrangente obra organizada por Minayo e Coimbra (2005), fruto do VII Congresso Latino-Americano de Ciências Sociais e Saúde, publicada pela FIOCRUZ, reunindo o principal da produção no continente.

Parte desse esforço da Associação foi narrada em publicação editada em colaboração por FIOCRUZ e ABRASCO (Lima; Santana, 2006), lançada no último Congresso Brasileiro da Associação, realizado no Rio de Janeiro em 2006. O evento alcançou caráter e repercussão mundial ao reunir as Associações de Saúde Púbica congregadas na Federação Mundial de Associações de Saúde Pública (WFHPA). Grande 
ênfase da publicação foi atribuída à trajetória histórica da área como um todo, sua participação nas políticas de saúde e sua legitimação institucional em função da presença envolvendo a realidade sanitária do país.

É necessário salientar, entretanto, que a institucionalização específica do subcampo das ciências sociais na grande área da saúde tornou-se possível, sobretudo, pelo esforço que a ABRASCO desenvolveu, através de seu núcleo crescente e persistente de militantes, a ponto de tornar-se uma das suas Comissões estáveis, com a característica de subárea disciplinar da Saúde Coletiva, juntamente com a Epidemiologia e a Comissão de Política e Gestão em Saúde (esta, uma área com um trajeto acadêmico por desenvolver-se ainda no campo, em parte devido a sua lógica predominantemente normativa e de intervenção institucional, diferente das duas anteriores).

O subcampo (ou subárea, se preferirmos uma denominação institucional) de Ciências Sociais, atualmente denominado Ciências Sociais e Humanas em Saúde, realizou, desde 1991, quatro Congressos de caráter nacional, além de vários eventos de âmbito regional, como Seminários, Reuniões, Encontros etc., em linha ascendente de participação, em termos quantitativos e qualitativos, assinalando-se a diversificação crescente de eixos temáticos de pesquisa, que deram origem a vários GTs da ABRASCO, predominantemente ligados à investigação das Ciências Sociais e Humanas, através de conceitos, teorias e métodos.

Apenas no último Congresso Brasileiro de Ciências Sociais e Humanas em Saúde, o terceiro congresso nacional da área da ABRASCO, realizado em Florianópolis em 2005, foram apresentados cerca de 3 mil trabalhos, com mais de 2 mil participantes, incluídos convidados, pesquisadores, alunos e profissionais da área da saúde. A qualidade dos trabalhos, assim como a diversidade dos temas, e a presença maciça e persistente dos congressistas foram marcantes no evento, patenteando o vigor da área.

No seu quarto Congresso Brasileiro, realizado em Salvador, em 2007, a área ganhou um caráter internacional, pois foi realizado conjuntamente com o Congresso da Associação Latino-americana de Medicina Social e a Associação Internacional de Políticas de Saúde. Mais de 4 mil pessoas compareceram ao evento, e mais de 3 mil trabalhos foram apresentados, incluídos pôsteres, comunicações, fóruns, palestras, painéis e mesas.

No campo da difusão da produção do conhecimento da área, a Revista Ciência e Saúde Coletiva, editada pela Associação, além de outros periódicos, é sinal do patrocínio do subcampo e de sua legitimação, considerada a oferta explosiva de trabalhos submetidos à avaliação para publicação. Com essa mesma perspectiva, vários periódicos surgiram na última década, incorporando conteúdos, áreas temáticas, abordagens conceituais e metodologias do campo das Ciências Sociais ao campo da Saúde Coletiva. Quase todas são indexadas em bases de primeira linha, com inserção internacional, como a SciELO. Há também periódicos multidisciplinares, como a revista Interface: Educação, Saúde, Comunicação ou História, Ciências, Saúde, Manguinhos, que vem beneficiando os estudos de ciências sociais na área da Saúde. Todas essas revistas tendem à legitimação da área de ciências sociais e humanas no campo da saúde e têm como centro de referência institucional e apoio a ABRASCO.

$\mathrm{O}$ que queremos dizer com isso, para finalizar este texto, é que essa associação tem, pelo conjunto de atividades, eventos e publicações que incentiva e patrocina, conferido efetiva legitimidade institucional ao campo das ciências sociais e humanas na área da saúde.

Já o contrário, isto é, a legitimação da área da saúde no campo das ciências sociais, como tema e como objeto de pesquisa, tem sido outra questão, bem mais complicada para se conduzir, tanto no plano acadêmico quanto institucional. Foi o que tentamos colocar no início deste artigo. Essa legitimação pode se fazer, como assinalamos páginas atrás, sem que o reconhecimento da produção dos cientistas sociais da área da saúde seja assegurado. Cabe, portanto, a nós, cientistas sociais que pesquisam e ensinam no complexo campo da saúde, continuar a desenvolver estratégias para que esse duplo reconhecimento científico se efetue: no campo das ciências da vida e no campo das ciências sociais e humanas.

Esta não tem sido uma tarefa fácil. 


\section{Referências}

CASTEL, R. Les métamorphoses de la question sociale - une chronique du salariat. Paris: Fayard, 1995. 490 p. (Col. Léspace politique).

CASTEL, R. L' insecurité sociale - Qu'est-ce qu'être protegé?. Paris: Seuil, 2003. 95 p.

HERZLICH, C. Saúde e doença no início do século XXI: entre a experiência privada e a esfera púbica. PHYSIS: revista de saúde coletiva. Rio de Janeiro, v. 14 , n. 2, p. 383-394, 2004.

HERZLICH, C. "Fragilidade da vida e desenvolvimento das ciências sociais no campo da saúde". Conferência ao III Congresso Brasileiro de Ciências Sociais e Saúde da ABRASCO. Florianópolis, 2005. In: CONGRESSO BRASILEIRO DE CIÊNCIAS SOCIAIS E SAÚDE DA ABRASCO, 3., 2005. Florianópolis. Anais... Florianópolis: ABRASCO, 2005. (1CD Rom)..

LIMA, N. T.; SANTANA, J. P. (Orgs.) Saúde Coletiva como compromisso: a trajetória da ABRASCO. Rio de Janeiro: FIOCRUZ/ABRASCO, 2006. 227 p.

LUZ, M. T. Novos saberes e práticas em Saúde Coletiva. São Paulo: HUCITEC, 2003. 174 p.

LUZ, M. T. Natural, racional, social - razão médica e racionalidade científica moderna. Rio de Janeiro: Campus, 1988.

LUZ, M. T. Natural, racional, social: razão médica e racionalidade científica moderna. 2. ed. São Paulo: Hucitec, 2004. 209 p.

LUZ, M. T. Fragilidade social e busca de cuidado na sociedade civil de hoje. In: PINHEIRO, R.; MATTOS, R. A. (orgs.) Cuidado: as fronteiras da integralidade. Rio de Janeiro: ABRASCO, 2004. p. 9-20.
LUZ, M. T. Cultura contemporânea e medicinas alternativas: novos paradigmas em saúde no fim do século XX. PHYSIS: revista de Saúde Coletiva. Rio de Janeiro, n.15 (suplemento), p. 145-176, 2005 a.

LUZ, M. T. Prometeu acorrentado: análise sociológica da categoria de produtividade e as condições atuais da vida acadêmica. PHYSIS: revista de Saúde Coletiva, v.15, n. 1, p. 39-58, 2005b.

LUZ, M. T. Novas práticas em Saúde Coletiva. In: MINAYO, M. C. S.; COIMBRA, C. E. A. (Orgs.) Críticas e atuantes - Ciências Sociais e Humanas em Saúde na América Latina. Rio de Janeiro: FIOCRUZ, 2005c. p. 33-46.

LUZ, M. T. Perda de ética no trabalho acadêmico: geração de sofrimento e doença entre trabalhadores universitários a partir do produtivismo como valor-fim entre pesquisadores docentes. In: PINHEIRO, R.; MATTOS, R. A. (orgs.). Razões públicas para a integralidade em saúde: $\mathrm{O}$ cuidado como valor. Rio de Janeiro: CEPESC-IMS/ UERJ-ABRASC0, 2007. p. 357-367.

LUZ, M. T. Notas sobre a política de produtividade em pesquisa no Brasil: consequências para a vida acadêmica, a ética no trabalho e a saúde dos trabalhadores. Política \& Sociedade: revista de sociologia política, v. 7, n. 13, p. 205-228, 2008.

MINAYO, M. C. S.; COIMBRA, C. E. A. (Orgs.) Críticas e atuantes - Ciências Sociais e Humanas em Saúde na América Latina. Rio de Janeiro: FIOCRUZ, 2005. $706 \mathrm{p}$.

PORCHMANN, M. Brasil, encruzilhadas do desenvolvimento: os retrocessos do atual modelo: Le Monde Diplomatique (Brasil), São Paulo, julho 2008, p. 4-5. 